
\title{
R Reseracth Sulure \\ Climate Change Adaptation in Agriculture: The Case of Small Southern Mediterranean Country
}

\author{
Abderrazek Ben Maatoug \\ University of Bisha \\ triki bilel ( $\nabla$ mtriki@ub.edu.sa ) \\ University of Bisha https://orcid.org/0000-0002-0696-392X \\ donia aloui \\ University of Carthage: Universite de Carthage
}

\section{Research Article}

Keywords: Climate change, Adaptation, crop yield losses, Cointegration in Panel Data, Insurance.

Posted Date: July 6th, 2021

DOI: https://doi.org/10.21203/rs.3.rs-555261/v1

License: (1) This work is licensed under a Creative Commons Attribution 4.0 International License.

Read Full License 


\title{
Climate Change Adaptation in Agriculture: The Case of Small Southern Mediterranean Country
}

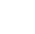

\begin{abstract}
In this study, we examined the effect of climate change on the incomes of farmers in a southern Mediterranean country. We proposed that crop insurance could be potentially used as a means to adapt to climate change. Using panel data for Tunisian regions, we were able to highlight the important effects of climate change on crops yields by considering two scenarios of the Representative Concentration Pathways, namely RCP 4.5 and RCP 8.5. In the long term (i.e., in 2050 and 2100), we expect increasingly frequent heat waves to occur, leading to a rise in droughts for all regions of Tunisia. We therefore recommend that farmers seek to insure themselves against the risks of drought and flood to their crops, because we feel this may be an attractive device for compensating them for any potential losses of income.
\end{abstract}

Keywords: Climate change; Adaptation; crop yield losses; Cointegration in Panel Data, Insurance. 


\section{Introduction}

Climate change now appears to be a proven phenomenon, and it has been found to be linked, at least in part, to emissions from human activity contributing to the greenhouse effect. Increasingly frequent heat waves, droughts, and forest fires are all indications of the serious consequences of climate change in 2021. The issue of climate change therefore demands new approaches to access resources and share risks, as well as the integration of the environmental issue into public policy choices. Climate change is a global phenomenon, but the effects of it are being seen at the regional level. Climate change prompts us to question how we manage the natural resources of our planet, and it puts our production methods to the test, especially for the agricultural sector.

Tunisia is an integral part of the Mediterranean Basin, a region that faces particularly high climatic risks. To better understand the effects of climate change on agriculture-as well as the challenges of adapting to, and mitigating, these effects-it is important to position Tunisia within the context of the Mediterranean Basin, where climate change is inevitably perceived as a threat to both nature and human life. Climate change affects crop yields through a complex interplay between crop-specific physiological effects and the availability of water resources in the short, medium, and long term. It is highly likely that spring and summer in Tunisia will become hotter and drier in the future. In addition, a decrease in the volume of surface water and groundwater is expected to follow increasingly frequent extended periods of drought (Lorenzo-Lacruz et al., 2013, 2017; Raymond et al., 2016). The major problem for farmers will be the frequency and duration of droughts, as posited by Nieto et al. (2010). These risks constitute a problem for the development of agricultural assets, which are needed to increase the incomes of farmers and reduce rural poverty (Dilley et al., 2005).

Over time, farmers have mastered cultivation techniques that are well suited to the local climatic conditions, yet climate change implies that these will need to be adapted, which in turn requires the rapid development of innovative economic and social practices. The use of insurance may be one such practice. Mitigation and adaptation measures in agriculture could rely on effective levers like specific insurance contracts to limit the economic impact of climate change. Insurance companies are now on the "frontlines" of climate change, which is turning out to be more of a threat than an opportunity. They can therefore help manage climate risk through products and services for agricultural activity to help limit the financial cost of harmful climatic events (Kath et al., 2018). 
The research tends to suggest that climate change will affect the future incomes of farmers in the form of unreliable crop yields. One way to adapt to this situation could comprise taking out an insurance policy that has been developed for the agricultural sector and the regional heterogeneity of climatic risks. Moreover, this work highlights the important implications of future episodes of drought for Tunisia by 2050-2100. The regional climate models (RCMs) of the EURO-CORDEX project constitute the basis for our analysis, which is based on the average emissions scenario RCP 4.5 and the pessimistic emissions scenario RCP 8.5.

Mediterranean agriculture is highly vulnerable to climatic phenomena such as drought, excessive or insufficient rainfall, heat waves, and so on, and such climatic phenomena threaten the financial stability of agricultural stakeholders. Studies carried out in the major Mediterranean economies have tended to reinforce the importance of developing cropinsurance products as a way to protect incomes against climatic risks (Di Falco et al., 2014).

A drought in the Mediterranean rainy season affects water resources by reducing the groundwater level and the water stored in reservoirs (Lorenzo-Lacruz et al., 2013, 2017; Raymond et al., 2016). In countries that are highly dependent on sufficient rainfall, such as North African countries, this lack of water has negative effects on economic activity, biodiversity, and crop yields (Turkes et al., 2020; Schilling et al., 2020). There is a general consensus these days about the alarming potential scenarios for droughts in the region, both climatic (Dubrovnik et al., 2014; Hertig \& Tramblay, 2017; Turkes et al., 2020) and hydrological (Forzieri et al., 2014). It is therefore essential to identify the implications of such possible situations for farmers' incomes in order to develop strategies to adapt, such as by using agricultural insurance. In addition, when adapting public policies, a more rigorous assessment of the economic effects of future droughts will need to incorporate dynamic modeling based on different climate scenarios (Escriva-Bou et al., 2017; Pulido-Velazquez et al., 2011; Van Loon et al., 2016).

The remainder of this paper is organized as follows: First, we present a literature review in the second section, and then the third section describes the data and methodology used in this study. The empirical results are then discussed in section four, before concluding remarks are given in the final section.

\section{Related literature:}

Over recent decades, meteorologists and environmental organizations have sought to raise public awareness of climate change. The phenomenon was first discussed in 1824, when the 
French mathematician and physicist Joseph Fourier discovered the greenhouse phenomenon and its effect on the atmosphere. Among other things, Fourier identified different modes of energy transfer between the Earth and its environment. He deduces that any change in the Earth's surface conditions could lead to a change in climate. The surface temperature changes according to the heat received and emitted, such that if the former is higher than the latter, the surface temperature increases, and vice versa.

With the considerable progress made in climatology over recent decades, there is now no doubt that the climate is changing. The creation of the Intergovernmental Panel on Climate Change (IPCC) helped highlight the importance of climate change and its socioeconomic effects. Faced with this reality, human activities are often identified as being responsible for these global atmospheric changes. Following the establishment of the IPCC over three decades ago, research into climate change grew exponentially. The Paris Climate Agreement set out several stages of implementation for the rapid reduction of greenhouse gas emissions in order to keep global warming below $2{ }^{\circ} \mathrm{C}$ by the end of the century. This agreement therefore aims to restrict the adverse effects of climate change, such as for the agricultural sector.

In recent times, we have seen increasingly frequent extreme weather events, and these have adversely affected agricultural yields and consequently the incomes of farmers (Ciscar et al., 2018; Bouwer, 2019). Heavy rains and droughts have resulted in production losses due to the vulnerability of crops. To compensate for this shortfall, some farmers have chosen to take out insurance policies to mitigate the risk by ensuring they will have a minimum income during periods of difficulty (Strunz, 2011; Pascual et al., 2015).

Having insurance companies help manage the risk of extreme climate-related events will require encouraging insurers to offer adequate cover against these risks and farmers to take them up. The insurance market is relatively new in Tunisia, which is a small country on the southern Mediterranean coast that is characterized by cold, rainy winters and hot, dry summers. Insurance companies that specialize in agriculture mainly insure against crop losses caused by natural disasters like drought, hailstorms, insects, frost, and so on. The setting of premiums based on risk management should be at the core of insurers' concerns given the increasingly frequent and severe natural disasters that have been seen in recent years. For the insurance industry, income from premiums often lags behind the growth in claims. What is more, with unpredictable but economically harmful events, merely considering historical data does not, in itself, lead to suitable insurance premiums (Tucker, 1997). 
In the agro-economic literature, climate change has been shown to have a significant potential effect on agricultural production, and the relationship between the two phenomena has been the subject of several studies (Wheeler \& Von Braun, 2013; Ruminta, 2016; Suryanto et al., 2020). Farmers will tend to see their incomes decline because of climate

136

137 change. Indeed, when faced with infrequent but damaging natural events, farmers will suffer significant financial losses. Research has posited that the best way to adapt to these unpredictable, extreme climatic risks is to seek insurance through government programs.

Jørgensen et al. (2020) analyzed farmers' use of insurance as a means to adapt to climate risks, highlighting that decisions on adapting to climate change depend on farm-management practices and the underwriting of crop-insurance contracts. Their study suggests that on the one hand, farmers with poor-quality, low-yield land tend to take out damage insurance due to the negative effects of natural disasters on their crops. On the other hand, farmers with better quality, high-yield land use agricultural management that is more suited to climate change, so they are less inclined to take out insurance against the losses caused by extreme weather events.

Based on data for a panel of Italian farmers, Di Falco et al. (2014) demonstrated the importance of insurance against natural disasters in maintaining the well-being of farmers by protecting against uncertainties in their income. They posited that climatic conditions will likely increase the demand for insurance products to reduce the exposure to risk. In addition, they showed that greater diversification of crops could also mitigate the effect of climatic hazards on crop yields by playing a hedging role.

\section{3- Empirical methodology:}

We sought to study the effects of global warming on crop yields and their variability. Econometric modeling therefore investigated the relationship that may exist between yield variability and meteorological factors.

Villavicencio et al. (2013) found that the temporal behavior of crop yields is not constant due to its strong dependence on climatic factors, so any estimates based on a level series will be spurious. Panel stationarity tests were carried out before proceeding with the study to investigate the dynamics between the different variables in the study. This can be estimated using the cointegration technique, which has two underlying advantages: First, it overcomes the difficulty associated with the narrowness of a time series, and second, it is more powerful than traditional time series tests (Banerjee, 1999). 


\subsection{Testing for Panel Stationarity and Cointegration}

The use of unit root and cointegration tests for econometric panel data offers a genuine advantage for dynamic models. Much research work has shown that there is a considerable improvement in the power of unit root tests when using panel data.

In recent decades, several researchers-such as Levin, Lin, and Chu (2002) and Im, Pesaran, and Shin (2003) — have proposed unit root tests for panel data structures, some of which we applied in this study. The tests used are generally based on the following ADF (Augmented Dickey-Fuller) equation:

$$
\Delta y_{i, t}=\alpha_{i}+\rho_{i} y_{i, t-1}+\sum_{j=1}^{p_{i}} \theta_{i, j} \Delta y_{i, t-j}+\varepsilon_{i, t}
$$

Where we assume the absence of a temporal effect and inter-individual dependencies, that is,

$$
E\left(\varepsilon_{i, t}, \varepsilon_{j, t}\right)=0 \quad \text { for all } i \neq j
$$

The second category of tests allows the heterogeneity of autoregressive roots under the alternative hypothesis to be established. These tests seem better suited to our regional panel data, since if the existence of a unit root can be rejected, the identification of autoregressive roots between the different regions is not likely. The test of Im, Pesaran and Shin (1997), or IPS for short, like the previous tests, is a joint test of the null hypothesis of unit root and the absence of fixed effects, but under the alternative hypothesis, they allow for the heterogeneity of the autoregressive roots in the different regions. Applying the IPS test is extremely simple because it is based on calculating the individual Dickey-Fuller statistics, and then a panel test statistic is derived from the mean and variance of individual t-statistics. Moreover, cointegration tests, in the case of panel data, can be considered a way of obtaining additional information when attempting to identify possible relationships between meteorological factors and crop losses.

As for unit root tests, the analysis of panel cointegration helps mitigate the low effectiveness of time series tests for small samples. The test that we present here has as its null hypothesis the absence of cointegration between several variables, while the alternative hypothesis depends on the degree of heterogeneity retained. Once again, this test assumes the absence of inter-individual dynamics and thus tests for the existence of intra-individual cointegration relationships. This test is based on the following long-term relationship: 


$$
y_{i, t}=\theta_{i}+\beta_{1, i} x_{1, i, t}+\ldots .+\beta_{m, i} x_{m, i, t}+\beta_{M, i} x_{M, i, t}+\varepsilon_{i, t}
$$

$$
\text { with } \mathrm{i}=1,2, \ldots, \mathrm{N} ; \mathrm{t}=1,2, \ldots, \mathrm{T} \text { and } \mathrm{m}=1,2, \ldots, \mathrm{M}
$$

Based on the same principle as the Engle and Granger tests for a time series, the procedures of Pedroni (e.g., Pedroni, 1996, 2000, 2007) test the residual stationarity of the long-term relationship estimated in the previous step, with the null hypothesis corresponding to the absence of cointegration. Pedroni's test allows the slope coefficients in the cointegration vector to vary across individual panel members (regions in this case). Pedroni uses seven residual-based panel cointegration statistics, four of which are based on pooling data within dimensions and three are based on pooling data between dimensions. The difference between the two types of tests is specified by the alternative hypothesis. The panel cointegration statistics constrain a common coefficient under the alternative hypothesis, while the group means cointegration statistics allow for heterogeneous coefficients under the alternative hypothesis. These statistics are then compared for the appropriate tails of the normal distribution. For this test, Pedroni allows for heterogeneity in the cointegration vectors and adjustment rates under the alternative hypothesis, which appears to be particularly relevant to our model given the significant regional differences observed in yield losses.

\subsection{Estimation Method: Fully Modified OLS versus Dynamic OLS}

Two popular techniques are often used to estimate the long-run relationship between cointegrated variables, namely the fully modified ordinary least squares (FMOLS) approach of Philips and Hansen (1990) and the dynamic ordinary least squares (DOLS) approach developed by Saikkonen (1991). FMOLS is a non-parametric approach for dealing with a serial correlation, and the basic idea behind this procedure is to eliminate endogeneity bias in the regressors and the serial correlation of errors (Pedroni, 2001, 2007). Pedroni (2007) suggests two procedures for applying this method to panel cointegration regression: the pooled panel FMOLS estimator (within dimensions) and the group-mean panel FMOLS (between dimensions). We chose to use the group-mean panel FMOLS because it deals with the common value and provides interesting results even with a short time series. DOLS, meanwhile, is an alternative parametric approach in which lags and leads are introduced to cope with the problems relating to the order of integration and the existence or absence of cointegration. 
To estimate the long-run relationship between crop yield losses and meteorological variables, we implemented the two alternative methods. We estimated the following long-run equation:

$$
\text { Corp_Yield_los }=\beta_{0}+\beta_{1} \text { Av_temp }+\beta_{2} \text { Min_temp }+\beta_{3} \text { Max_temp }+\beta_{4} \text { Cum_pluv }+\varepsilon_{i, t}
$$

\subsection{Extrapolation of Yield Losses based on Climate Change Scenarios}

Climate projections were used to predict the relevant meteorological conditions for the various regions in order to determine the impact of climate change on future crop yields. The emission scenarios in the Special Report Emissions Scenarios (SRES) ${ }^{1}$ show how greenhouse gas emissions may evolve over this century.

For our climate projections, we used the scenarios of the EURO-CORDEX Project as the basis for our simulations, which were carried out in relation to two long-term periods of the Coupled Model Intercomparison Project (CMIP), which developed new climate scenarios as part of an international collaboration. The IPCC, meanwhile, has identified four routes for greenhouse gas (GHG) evolution in the atmosphere in the form of its representative concentration pathways (RCPs).

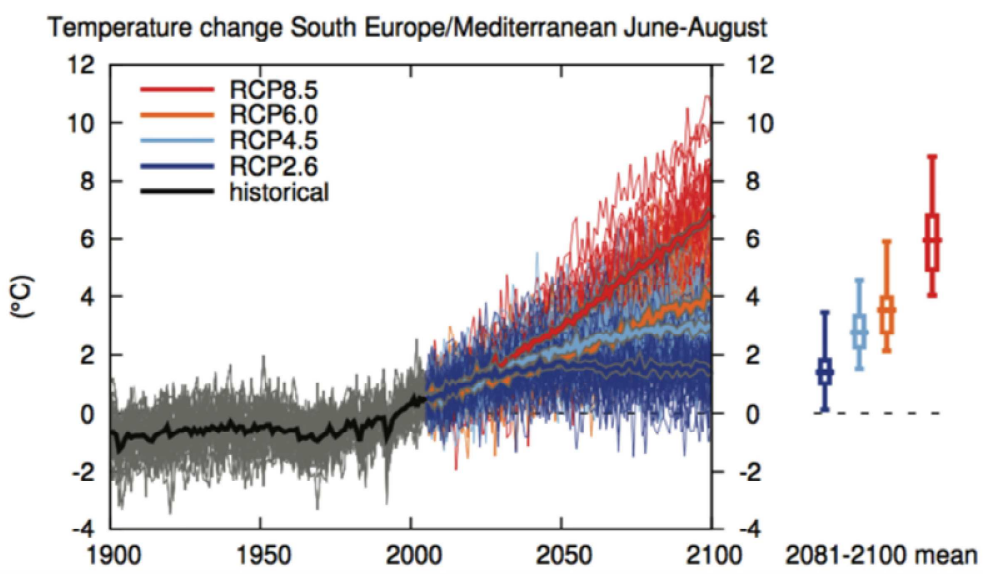

Fig. 1: Variations in mean global surface temperature $\left({ }^{\circ} \mathrm{C}\right)$ in relation to the four typical scenarios of the IPCC

The EURO-CORDEX project uses temperature and precipitation as the basis for simulating 14 regional climate models. The Tunisian National Meteorological Institute, as an associate of the EURO-CORDEX project, carries out climate forecasts for the entire territory. The changes in temperature and cumulative rainfall were calculated for two emission scenarios, namely the average scenario RCP 4.5 and the pessimistic scenario RCP 8.5.

\footnotetext{
${ }^{1}$ The SRES of the IPCC describes various future scenarios for greenhouse gas emissions.
} 
Explicit policies to limit greenhouse gas emissions or adapt to global climate change are included, so the United Nations Framework Convention on Climate Change is taken into account.

For the Mediterranean region, Figure 1 indicates an expected increase in ground temperature of $2-6^{\circ} \mathrm{C}$ by 2100 , depending on the season. Heat waves and droughts also become increasingly frequent (Jacob et al., 2014). In addition, most of the Mediterranean Basin will experience even hotter summers in the near future, with temperatures above the 254 current norm for the season.

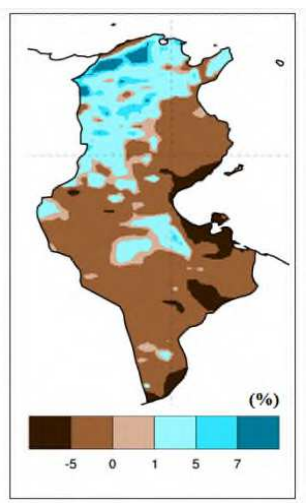

RCP4.5 H2050

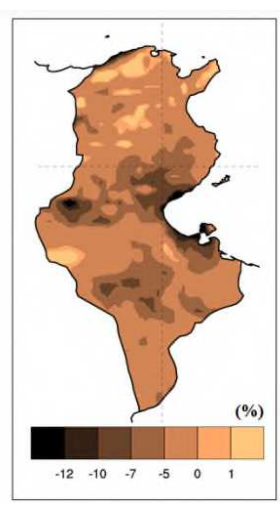

$\mathrm{RCP} 4.5 \mathrm{H} 2100$

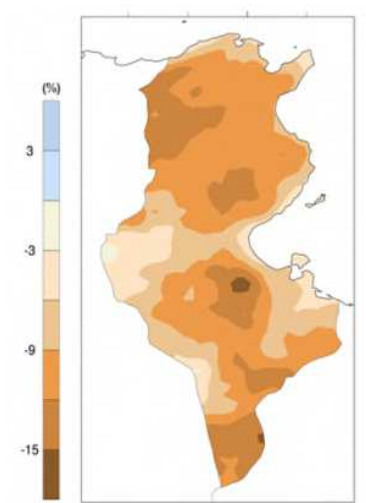

RCP8.5H2050

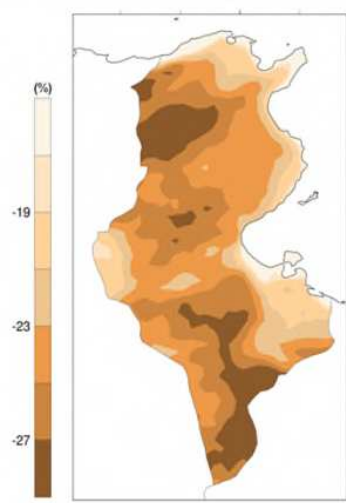

RCP8.5H2100

Fig. 2. Evolution of total annual rainfall for 2050 and 2100 according to RCP 4.5 and 8.5

For this study, we used the two RCP scenarios for the years 2050 and 2100. These show a significant increase in temperature coupled with a decrease in rainfall for the entire country. The simulations show a clear decrease in cumulative annual precipitation for both the 2050 and 2100 horizons. At the end of the century, we see a decrease of around 5-20\% under the RCP 4.5 scenario and a decrease of around 18-27\% under the RCP 8.5 scenario (Figure 2). A spatial climate disparity emerges by 2100 , particularly in the south-central part of the country (especially between Sfax and Gabes in), the north-west of the country (Jendouba and Le Kef Governorates), and in desert zone of Tunisia (Tataouine Governorate).

The temperature simulations that we carried out using the INM simulator showed a high degree of variability for the different regions, with a temperature increase of $3^{\circ} \mathrm{C}$ under the $\mathrm{RCP} 4.5$ scenario and an increase of more than $5^{\circ} \mathrm{C}$ under the RCP 8.5 scenario (Figure 3 ). 


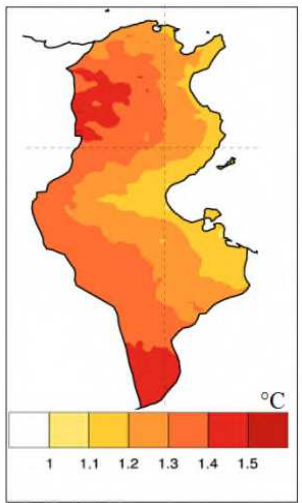

RCP4.5 H2050

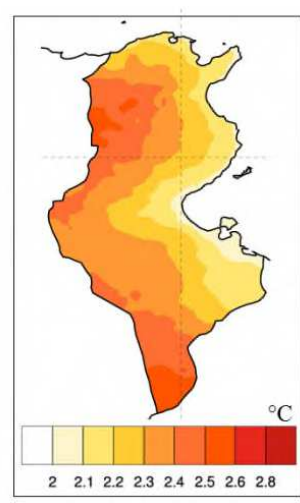

$\mathrm{RCP} 4.5 \mathrm{H} 2100$

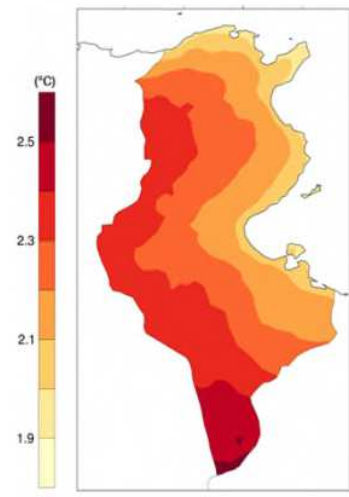

RCP8.5H2050

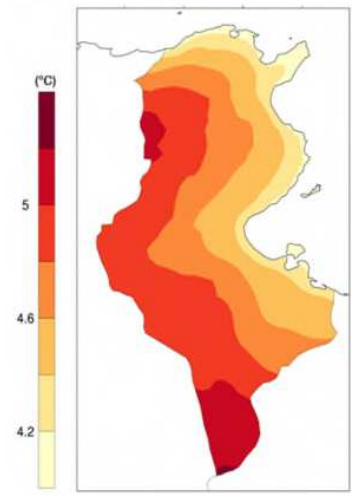

RCP8.5H 2100

Fig. 3. Evolution annual mean temperature for 2050 and 2100 according to RCP 4.5 and 8.5

\section{Empirical results:}

\subsection{Data:}

For our empirical study, we used panel data for the regions with observations on an annual basis for yield losses and meteorological parameters, namely temperature and precipitation for the 1980-2018 period. These data cover the main agricultural regions of Tunisia in different climatic zones, namely Beja, Bizerte, Gabès, Gafsa, Tunis, Jendouba, Kasserine, Mednine, Monastir, and Sfax. This data derives from different sources, including the National Agricultural Observatory (ONAGRI), the Tunisian Ministry of Agriculture, the National Meteorological Institute (INM), and the Food and Agriculture Organization (FAO).

The variable "Yield losses" was calculated as follows:

Yield losses $=$ Expected crop per area planted (for t time and i region) -

Mean crop yield (for $\mathrm{t}$ time and i region).

To characterize climate change, we used temperature (minimum and maximum) and precipitation as climate attributes. We used the cumulative precipitation for September to March, which is the rainy season in the southern Mediterranean.

\subsection{Results:}

The procedure for estimating the relationship between the "Yield losses" variable and the independent variables (temperature and precipitation) comprised four steps: (i) unit root panel tests; (ii) panel cointegration tests to identify long-term equilibrium relationships; (iii) the FMOLS and DOLS estimation methods to estimate this relationship; and finally (iv) the use of these estimates to forecast crop yield losses for 2050-2100. 


\subsubsection{Panel unit root tests}

The presence of non-stationarity in a statistical series leads to spurious regressions, but the use of unit root tests allows us to check for possible non-stationarity in such series. To ensure the stationarity of the selected variables, we performed the Levin-Lin-Chu, Im-PesaranShin, Fisher-ADF, and Fisher-PP unit root tests on the series at level and first difference. The results of these tests are presented in Table 1. All the tests suggest that the Crop_Yields_los and Av_temp are non-stationary. For the other variables-Min_temp, Max_temp, and Cum_pluv-we applied the majority rule (three tests against one) to conclude nonstationarity. The test results confirm that all the variables were stationary at first difference.

Table 1: The Results of Panel Unit Root Tests

\begin{tabular}{|c|c|c|c|c|c|c|c|c|}
\hline & \multicolumn{2}{|c|}{ IPS W- } & \multicolumn{2}{|c|}{ Levin, Lin, } & \multicolumn{2}{|c|}{ PP- Fisher } & \multicolumn{2}{|c|}{ ADF-Fisher } \\
\hline & Level & First & Level & First & Level & First & Level & First \\
\hline Crop_Yiel & -1.23 & - & -1.21 & - & 21.523 & $112.364 *$ & 20.636 & 101.144 \\
\hline Av_temp & -1.15 & - & -1.27 & - & 21.264 & $67.012 * *$ & 21.37 & $65.676^{*}$ \\
\hline Min_temp & - & - & $-3.45 * \star$ & - & 9.782 & $78.521 * *$ & 9.511 & 76.607 * \\
\hline Max_temp & -0.98 & - & -1.24 & - & 33.536 & $126.37 * \star$ & 31.124 & 124.18 * \\
\hline Cum_pluv & - & - & $-1 \cdot 348$ & - & 20.24 & $234.145 *$ & 19.314 & 212.438 \\
\hline
\end{tabular}

\subsubsection{Cointegration Test:}

The Kao (1999) test and the Pedroni (2004) test are widely used in the literature to test for cointegration between variables (Table 2). Equation 4 expresses the long-term relationship between Corp_Yield_los, Av_temp, Min_temp, Max_temp, and Cum_pluv.

As indicated in Table 2, the Pedroni and Kao tests indicate that the null hypothesis of no cointegration can be rejected for all regressors at a $1 \%$ significance level (five against three). This implies that there is a long-run relationship between yield losses and climatic factors.

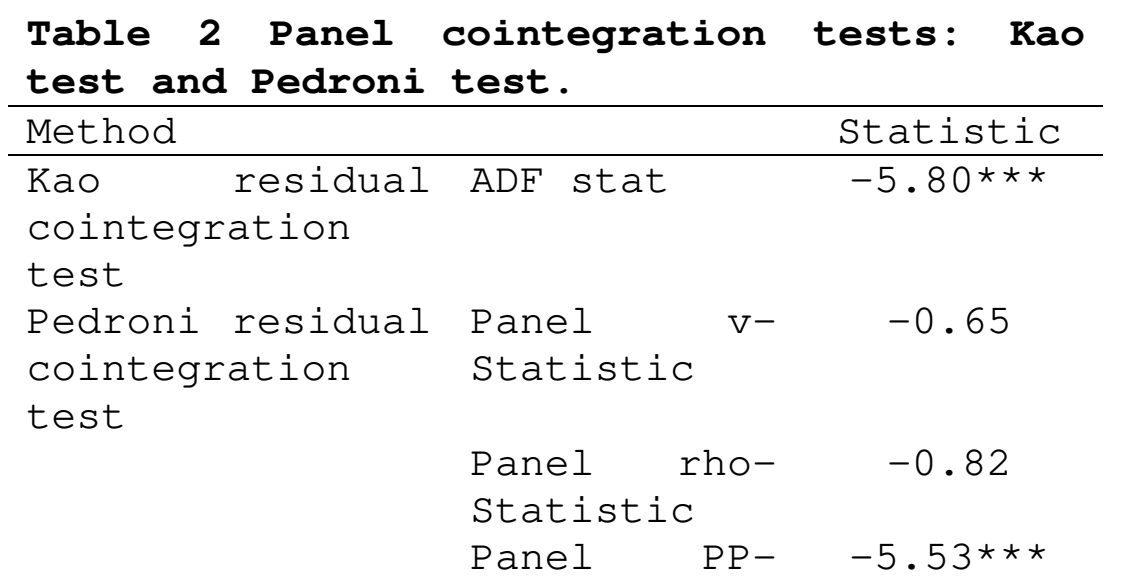




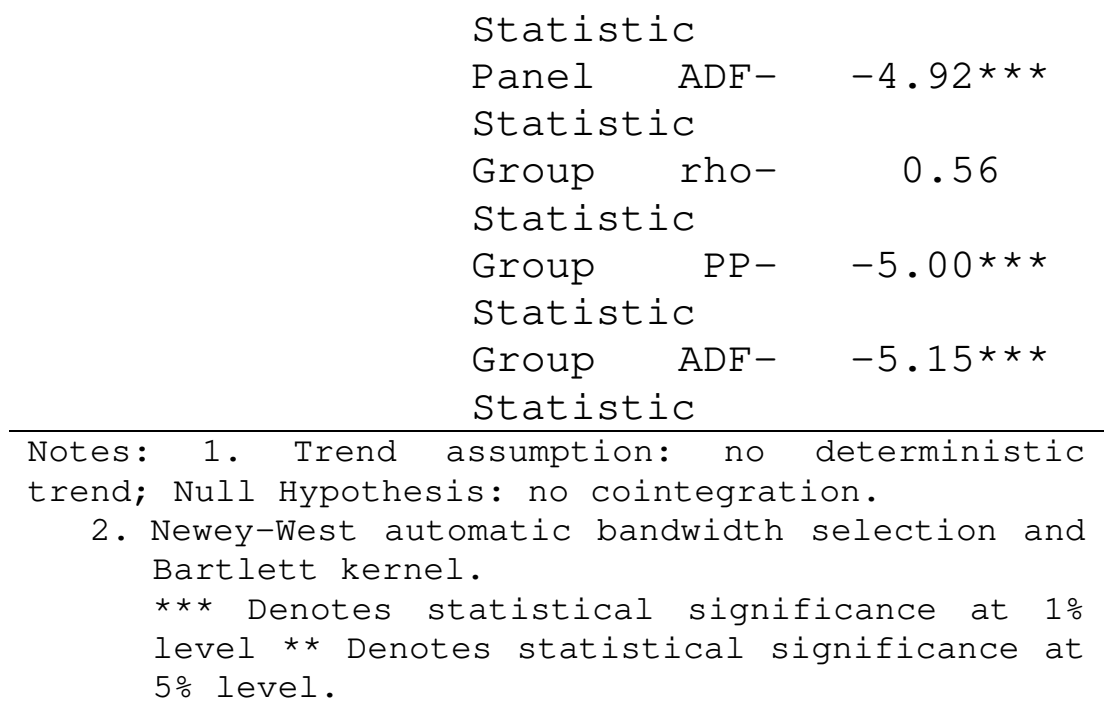

313

314

315

316

317

318

319

320

321

322

323

324

\subsubsection{Estimation:}

Given the existence of a long-term relationship among the variables, we estimated equation 4 using the FMOLS and DOLS methods. Table 3 presents the estimated coefficients for the long-run relationship between yield losses and the climate variables. The cointegration results indicate that the maximum temperature has a positive and significant influence on yield losses, with an increase of $1 \%$ in maximum temperature leading to a decrease in crop yields of around $0.32 \%$. In contrast, the minimum temperature has a negative and significant effect on yield losses, with a $1 \%$ increase in minimum temperature leading to a decrease in yield losses (i.e., an increase in crop yields) of $0.29 \%$. Precipitation also has a statistically strong effect on yield losses. Historically, rainfall between September and March in Mediterranean countries plays a very important role in crop yields, because the demand for water for cereal crops is high during this period.

\begin{tabular}{|c|c|c|}
\hline & FMOLS & DOLS \\
\hline \multicolumn{3}{|c|}{ Crop_Yields_los } \\
\hline Min_temp & $-0.29 * \star \star$ & $-0.31 * \star \star$ \\
\hline Max_temp & $0.32 * \star *$ & $0.20 * \star \star$ \\
\hline Cum_pluv & $-0.94 * *$ & $-0.92 * *$ \\
\hline
\end{tabular}

\subsubsection{Extrapolations and forecasts:}

Global-level climate modeling has allowed researchers in the field of agricultural production to consider multiple scenarios for projecting the effect of climate change on crop 
332

yields (Flato et al., 2013), and recent studies have incorporated future climate scenarios into crop simulation models at the regional level (Dixit et al., 2018; Zhang et al., 2019). Our empirical work sought to assess the impact of climate change on the productivity of agricultural land, and the results are presented in the following table:

Table 4. Crop yields losses projection with

\begin{tabular}{ccccc}
\hline & \multicolumn{1}{c}{ Scenario } & RCP & 4.5 & \multicolumn{2}{c}{ Scenario } & RCP 8.5 \\
\hline North region & 2050 & 2100 & 2050 & 2100 \\
Jendouba & -50.12 & -7.03 & 93.36 & 179.61 \\
Beja & -28.57 & 4.91 & 43.10 & 110.14 \\
Bizerte & -24.37 & -5.98 & 36.78 & 153.05 \\
Tunis & -12.62 & 17.05 & 38.19 & 84.9 \\
Central region & & & & \\
Monastir & 10.19 & 13.62 & 30.50 & 71.17 \\
Kasserine & -14.35 & 1.69 & 26.12 & 69.58 \\
Sfax & 9.98 & 14.02 & 14.01 & 41.96 \\
South region & & & & \\
Gabes & 7.12 & 9.49 & 11.05 & 33.07 \\
Gafsa & -4.58 & 7.91 & 6.35 & 37.55 \\
Medenine & 9.84 & 13.81 & 9.9 & 37.45 \\
\hline
\end{tabular}

The crop yields in the different regions are strongly dependent on rainfall levels, a general increase in temperature, and the scarcity of water resources. Due to droughts being expected by 2050-2100, agricultural activity is threatened, especially in the center and south of the country.

The results of these projections for crop yield losses suggest that climate change will lead to a worsening financial situation for farmers, especially in the central and southern regions of Tunisia, with crop yield losses of more than 7 quintals/hectare. In the northern regions, the projections are less pessimistic because crops will be less affected by climate change, especially under the RCP 4.5 scenario.

In addition, the effect of the future climate on crop yields is more severe under the RCP 8.5 scenario for all the regions, with even the northern regions of the country now being very affected.

\subsubsection{Insurance as Way to Adapt to Climate Change}

The agricultural sector is relatively vulnerable to climate change, so it will be heavily affected by it. One of the most damaging aspects of climate change for Tunisia is increased drought, which will harm food production and consequently affect the incomes of farmers. 
The creation of a compensation fund for agricultural damage caused by natural disasters in 2018 was aimed at compensating farmers for any damage suffered.

This fund is based on an index compensation system based on the insurable area and the nature and severity of climatic risks. It provides compensation for agricultural damage caused by natural disasters, such as floods, storms, winds, droughts, snow, and frost. The compensation rate for farmers is set at $60 \%$, while a membership fee for farmers is calculated at $2.5 \%$ of the cost or estimated value of crop yields, depending on their preference. A premium that is paid by farmers is calculated by multiplying the premium rate by the expected crop yield for the coming year.

Insurance allows farmers to protect themselves against the extreme climatic events that may affect their farms, so it represents a way of adapting to the risks brought by climate change. Through insurance, the burden of income losses due to climatic events is therefore shared with the government and other participants in the compensation fund. ${ }^{2}$ Insurance theory predicts the premium will increase as the risks from climate change increase.

The projections made based on the cointegration relationship for yield losses show that there will be a significant increase in crop losses. Climatic disasters are infrequent, however, and this limits the ability of insurance companies to assess and determine the level of risk. Higher prices are therefore a likely consequence of the increased uncertainty facing insurance companies.

Without government intervention, these potential long-term losses will result in higher insurance premiums and possibly the withdrawal of insurance companies from this market. The insurance system will therefore vary in terms of viability and efficiency, but the introduction of public-sector insurance makes it possible to overcome the shortcomings of the free market in providing cover for extreme climatic risks. In some countries, agricultural insurance is subsidized by governments through national production protection programs. The United States, in particular, is pursuing targeted actions through the Federal Crop Insurance Program. France, meanwhile, has set up a National Fund for Risk Management in Agriculture (FNGRA $)^{3}$ in order to promote the financing of mechanisms for managing climatic and environmental hazards in the agricultural sector. In Morocco, the Fund against Catastrophic Events (FSEC) 4 compensates the victims of a catastrophic event who are either not covered or not indemnified to the same level that is provided for by the fund, in which case the fund tops

\footnotetext{
${ }^{2}$ The Agricultural Damage Compensation Fund began operating on October 28, 2019.

${ }^{3}$ This fund was established by law no. 64-706 of July 10, 1964 codified in articles L. 361-1 et seq. The rural and maritime fishing code is managed by the Caisse centrale de réassurance (CCR).

${ }^{4}$ The implementation date of this fund corresponds to 2020 .
} 
up compensation. In Italy, on the other hand, the absence of an insurance system supported by the state and the limited availability of private insurance makes it inevitable that state resources will inevitably need to be mobilized to compensate farmers affected by natural disasters.

\section{Conclusion}

The cointegration model estimation for the panel data allowed us to observe regional disparities in the effect of climate change on the productivity of agricultural land. These results, when related to climate change scenarios, should enable farmers to better adapt and better plan for the possible risks, such as by taking out crop insurance.

The projections based on the two scenarios RCP 4.5 and RCP 8.5 show an increased risk of yield losses, especially in some higher risk regions. This suggests that the demand for agricultural insurance in Tunisia could increase in a future that seems likely to be characterized by greater and more frequent climatic events. Mitigation and adaptation measures for climate change should therefore be taken to cope with the potential yield losses. In Tunisia, heat waves in recent years have given rise to fires that have affected crops, resulting in damage to farmers' incomes, the environment, and biodiversity. In future, such phenomena may intensify and cause some farmers to give up on agricultural production.

Given the risks faced by farmers, crop insurance presents a means for adapting to climate change by protecting against income fluctuations caused by variations in rainfall and temperature. An alternative way of adapting involves educating farmers about good practices for water use and agricultural productivity. While this will not prevent episodes of drought, it will shield the agricultural sector from some of the resulting difficulties and socioeconomic disruption.

Code availability The code used in the current study is available from the corresponding author on reasonable request.

Authors' contributions Conceptualization: A.B.M., M.B.T. and D.A. Methodology: A.B.M., M.B.T. Validation: A.B.M. and M.B.T. Formal analysis: A.B.M., M.B.T. and D.A. Investigation: A.B.M., M.B.T. and D.A. Writing-original draft: A.B.M., M.B.T. and D.A. Writing-review and editing: A.B.M. and M.B.T. Funding acquisition: A.B.M. and M.B.T. Resources: A.B.M. and M.B.T. Supervision: A.B.M. and M.B.T.

Funding Not applicable

Availability of data The data sets are not publicly available but may be obtained from the authors upon reasonable request and with the permission of the National Agricultural Observatory (ONAGRI), the Tunisian Ministry of Agriculture and the National Meteorological Institute (INM). 


\section{Declarations}

415

Conflicts of interest The authors declare no competing interests.

Ethics approval Not applicable

Consent to participate Not applicable

\section{References}

- Banerjee, A. (1999), Panel Data Unit Roots and Cointegration: An Overview, Oxford Bulletin of Economics and Statistics, 61, 607-629.

- Di Falco. S. 2014. Adaptation to climate change in Sub-Saharan agriculture: assessing the evidence and rethinking the drivers. European Review of Agricultural Economics Vol 41 (3) (2014) pp. 405-430 doi:10.1093/erae/jbu014.

- Dilley, M. Chen, R.S. Deichmann, U. M. A.L. Lerner-Lam, M. Arnold, J. Agwe, G. Yetman, 2005. Natural Disaster Hotspots: A Global Risk Analysis, The International Bank for Reconstruction and Development/The World Bank and Columbia University, Washington, D.C,.

- Dixit, A., Kumar, N., and Kumar, S. (2018). Use of generic medicines. J. Health Manag. 20, 84-90. doi:10.1177/0972063417747747

- Flato, G. Marotzke, J. Abiodun, B. Evaluation of climate models T.F. Stocker, D. Qin, G.K. Plattner, et al. (Eds.), Climate Change 2013: the Physical Science Basis. Contribution of Working Group I to the Fifth Assessment Report of the Intergovernmental Panel on Climate Change, Cambridge University Press, Cambridge and New York (2013), pp. 743-866

- Im, K.S., Pesaran, M.H., Shin, Y., 2003. Testing for unit root in heterogeneous panels. J. Econom. 115, 5374.

- Jacob D, Petersen J, Eggert B, Alias A, Christensen OB, Bouwer LM, Braun A, Colette A, Déqué M, Georgievski G, Georgopoulou E, Gobiet A, Menut L, Nikulin G, Haensler A, Hempelmann N, Jones C, Keuler K, Kovats S, Kröner N, Kotlarski S, Kriegsmann A, Martin E, van Meijgaard E, Moseley C, Pfeifer S, Preuschmann S, Radermacher C, Radtke K, Rechid D, Rounsevell M, Samuelsson P, Somot S, Soussana J-F, Teichmann C, Valentini R, Vautard R, Weber B, Yiou P (2014) EURO-CORDEX: new high-resolution climate change projections for European impact research. Regional Environmental Change, 14(2), 563-578

- Jørgensen, F. J., Bor, A., and Petersen, M. B. (2020). Compliance without Fear: predictors of protective behavior during the first wave of the COVID-19 pandemic. PsyArXiv [Preprint].

- Kao C, Chiang M. 2000. the estimation and inference of a cointegrated regression in panel data. Adv Econ; 15:179-222.

- Kath J., Mushtaq S., Henry R., Adeyinka A. Stone R. 2018. Index insurance benefits agricultural producers exposed to excessive rainfall risk. Weather and Climate Extremes V. 22, December, Pages 1-9. https://doi.org/10.1016/j.wace.2018.10.003.

- Levin, A., Lin, C.-F., Chu, C.-S.J., 2002. Unit root tests in panel data: asymptotic and finite sample properties. J. Econom. 108, 1-24. 
- Lorenzo-Lacruz, J., Garcia, C. and Morán-Tejeda, E. 2017. Groundwater level responses to precipitation variability in Mediterranean insular aquifers. Journal of Hydrology, 552, 516-531. https://doi.org/10.1016/J.JHYDROL.2017.07.011.

- Lorenzo-Lacruz, J., Morán-Tejeda, E., Vicente-Serrano, S.M. and López-Moreno, J.I. 2013. Streamflow droughts in the Iberian Peninsula between 1945 and 2005: spatial and temporal patterns. Hydrology and Earth System Sciences, 17(1), 119-134. https://doi.org/10.5194/hess-17-119-2013.

- McGuire, M. 2010. "Finance and Growth: An Analysis of Causality for Cointegrated Panels", thesis for bachelor degree, Willams College, Massachussets.

- Ntukamazina N. Onwonga R.N. Sommer, R. Claude, J. Mukankusi, C.M. Mburu, J. Kariuki, R. 2017. Index-based agricultural insurance products: challenges, opportunities and prospects for uptake in sub-Sahara Africa, J. Agric. Rural Dev. Tropics Subtropics 118 (2) 171-185.

- Nieto, J.D. Cook, S.E. Laderach, P. Fisher, M.J. Jones, P.G. 2010. Rainfall index insurance to help smallholder farmers manage drought risk, Clim. Dev. 2 233-247,http s://doi.org/10.3763/cdev.2010.0050.

- Pedroni. 2007, "Social capital, barriers to production and capital shares: implications for the importance of parameter heterogeneity from a nonstationary panel approach", Journal of Applied Econometrics, vol 22, no $2,429-451$

- Pedroni, P. 1996. Fully modified OLS for heterogeneous cointegrated panels and the case of purchasing power parity, Indiana University Working Papers in Economics No. 96-020.

- Pedroni, P. 2000. Fully modified OLS for heterogeneous cointegrated panels, Advances in Econometrics, 15, 93-130.

- Pedroni, P. 2004. Panel cointegration: asymptotic and finite sample properties of pooled time series tests with an application to the PPP hypothesis, Econometric Theory, 20, 597-627.

- Phillips, P. and Hansen, B. 1990. Statistical Inference in Instrumental Variables Regression with I(1) Processes. Review of Economic Studies, 57, 99-125.

- Raymond, C.M. Gottwald, S. Kuoppa, J. Kyttä M. 2016 .Integrating multiple elements of environmental justice into urban blue space planning using public participation geographic information systems Landsc. Urban Plan., 153 (), pp. 198-208, 10.1016/j.landurbplan.2016.05.005

- Shweta Sinha. 2019. Agriculture Insurance for Climate Change Adaptation and Disaster Resilience in ASEAN Part of the Disaster Risk Reduction book series (DRR).

- Sisse Liv Jørgensena, Mette Termansenb, Unai Pascual. 2020. Natural insurance as condition for market insurance: Climate change adaptation in agriculture. Ecological Economics. 169.

- Stern, N. 2006. "Stern Review on the Economics of Climate Change", Population and Development Review, Vol 32, Issue 4, December, 793-798,

- Sturm, T. and Oh, E. 2010. "Natural disasters as the end of the insurance industry? Scalar competitive strategies, Alternative Risk Transfers, and the economic crisis”, Geoforum, N 41, 154-163

- Suryanto*, Evi Gravitiani and Akhmad Daerobi. 2020. Crop insurance as farmers adaptation for climate change risk on agriculture in Surakarta residency Indonesia. Int. J. Trade and Global Markets, Vol. 13, No. 2.

- Suryanto. B. et al 2020. Temperature dependence and activation energy of electrical conduction in an engineered cementitious composite. : IOP Conf. Ser.: Mater. Sci. Eng. 930012053.

- Trærup, S. L.M. (2012): "Informal networks and resilience to climate change impacts: A collective approach to index insurance", Global Environmental Change, Vol 22, issue 1, pp 255-267. 
- Tucker M. 1997. Climate change and the insurance industry: the cost of increased risk and the impetus for action. Ecol Econ 22:85-96. doi:10.1016/S0921-8009(96)00556-3

- Vergara, O., Zuba, G., Doggett, T., and Seaquist, J. 2008. "Modeling the Potential Impact of Catastrophic Weather on Crop Insurance Industry Portfolio Losses”, American Journal of Agricultural Economics, Vol 90, $\mathrm{N}^{\circ} 5,1256-1262$

- Villavicencio, X., McCarl, B.A., Wu, X.M., and Huffman, W.E. 2013. Climate Change Influences on Agricultural Research Productivity. Climatic Change. 119 (3-4): 815-24. DOI 10.1007/s10584-013-0768-6.

- Walker, T. S., Singh, R. P., and Asokan. M. (1986): "Risk Benefits, Crop Insurance, and Dryland Agriculture", Economic and Political Weekly, Vol 2, N²5/26, A81-A88.

- Wheeler, T. and Von Braun, J. 2013. "Climate change impacts on global food security", Science, Vol. 341 No. 6145, pp. 508-513, doi: 10.1126/science.1239402.

- Zhang X. Liu. L. Henebry. G. 2019. Impacts of land cover and land use change on long-term trend of land surface phenology: a case study in agricultural ecosystems. Environ. Res. Lett. 14044020 